\title{
PENGARUH FAKTOR PREDISPOSISI PENDUKUNG DAN PENDORONG IBU TERHADAP PEMBERIAN ASI EKSKLUSIF DI WILAYAH KERJA PUSKESMAS PANGIRKIRAN KECAMATAN HALONGONAN KABUPATEN PADANG LAWAS UTARA TAHUN 2015
}

\author{
Ica Fauziah Harahap ${ }^{1}$, Albiner Siagian ${ }^{2}$,Elmina Tampubolon ${ }^{3}$ \\ ${ }^{1}$ Alumni Program Studi S2 Ilmu Kesehatan Masyarakat STIKes DHDT \\ ${ }^{2}$ Staf Pengajar Program Studi Ilmu Kesehatan Masyarakat USU \\ ${ }^{3}$ Staf Pengajar Program Studi Ilmu Kesehatan Masyarakat STIKes DHDT
}

\begin{abstract}
Maternal breast feedy is the best nutrition at the early age of the baby's life. Exclusive breastfeeding is given only breast milk for baby without any additional food up to six months old. The Target exclusive breastfeeding in the Health Service of North Padang Lawas District is $85 \%$ but the scope of exclusive breastfeeding in the Puskesmas of Pangirkiran in February 2014 amounted to $30.5 \%$ and the scope of exclusive breastfeeding in August 2014 amounted to 36.2\%. This study was an observational research design with a case-control and the study aims to analyze the influence of predisposing factors (knowledge, attitudes), enabling factors (lactation), reinforcing factors (family support, support health workers) loward exclusive breastfeeding in the working area Puskesmas of Pangirkiran Halongonan sub district of Halongonan district of North Padang Lawas. The Population of this research is all breast feedy mothers who has baby in 6-12 months. The sample is 144 people consist of is people in 72 cases and 72 controls. Based on the results of the study indicate the variables of knowledge, attitude, lactation, family support and support health workers influence on exclusive breastfeeding. Expected to health workers in health centers in the Puskesmas Pangirkiran to further improve counseling on exclusive breastfeeding to the public so that exclusive breastfeeding to the baby can be improved.
\end{abstract}

Keywords: Behavior, exclusive breastfeeding

\section{PENDAHULUAN}

Air Susu Ibu (ASI) merupakan nutrisi terbaik pada awal usia kehidupan bayi. ASI Eksklusif diberikan hanya ASI saja tanpa bahan makanan tambahan sampai usia bayi enam bulan. ASI ibarat emas yang diberikan gratis oleh Tuhan karena ASI adalah cairan hidup yang dapat menyesuaikan kandungan zatnya yang dapat memenuhi kebutuhan gizi bayi. Sejak masa kehamilan, janin menerima nutrisi dari ibu melalui plasenta. Pada masa bayi di dalam tubuh ibu secara alami telah disediakan makanan yang dibutuhkan untuk perkembangan dan pertumbuhan selanjutnya berupa ASI (Kristiyansari, 2009).

Pentingnya pemberian ASI secara Eksklusif merupakan masalah yang tidak asing lagi, namun tiap tahunnya cakupan ASI Eksklusif masih belum tercapai sesuai dengan target yang diinginkan. Pemerintah telah menghimbau pemberian ASI secara Eksklusif, hal ini terbukti adanya Keputusan Menteri Kesehatan Nomor: 450/Menkes/SK/IV/2004 dikatakan untuk mencapai pertumbuhan, perkembangan dan kesehatan optimal, bayi harus diberi ASI Eksklusif selama 6 bulan pertama, selanjutnya untuk kecukupan nutrisi bayi mulai diberi makanan pendamping ASI yang cukup aman, dengan pemberian ASI dilanjutkan sampai 2 tahun (Pohan, 2011).

Survey awal yang dilakukan di Kecamatan Halongonan, dari 185 ibu yang menyusui terdapat 72 ibu menyusui yang memberikan ASI Ekslusif pada bayinya dan $113 \mathrm{ibu}$ menyusui tidak memberikan ASI Eksklusif pada bayinya dengan alasan ketidaktahuan tentang ASI Eksklusif. Ibu terkadang sudah memberikan makanan padat pada bayinya yang seperti pisang, bubur ataupun nasi tim. Banyak ibu-ibu yang berpendapat apabila bayinya menangis itu karena sedang lapar sehingga mereka memberikan makanan padat. Selain itu mereka beranggapan ASI saja tidak cukup untuk memenuhi kebutuhan bayinya.

Sumatera Utara khususnya di Medan, pemberian ASI Eksklusif pada bayi sangat menurun dikarenakan banyaknya ibu-ibu yang tidak paham tentang pemberian ASI Eksklusif, berdasarkan hasil penelitian 
terdahulu di sebuah Puskesmas, dikatakan dari sekitar 30 ibu-ibu yang menyusui, yang memberikan ASI Eksklusif kepada bayinya hanya sekitar 8 orang dengan yang memiliki pengetahuan baik 7 orang $(23,33 \%)$, yang memiliki pengetahuan cukup baik 15 orang $(50,00 \%)$, dan masih ada sekitar 8 orang $(26,67 \%)$ yang memiliki pengetahuan kurang baik yang disebabkan kurangnya informasi tentang ASI Eksklusif.

Perilaku menyusui berkaitan dengan pengetahuan yang kurang, kepercayaan atau persepsi dan sikap yang salah dari ibu mengenai ASI. Dukungan suami, keluarga, tenaga kesehatan dan masyarakat sangat diperlukan agar ibu dapat menyusui secara eksklusif. Ibu sebagai bagian dalam keluarga memegang peranan sangat penting dalam upaya ini (Yuliarti, 2008).

Puskesmas sebagai sarana pelayanan kesehatan dasar mempunyai peran yang cukup penting dalam pelaksanaan pemberian ASI Eksklusif. Pelaksanaan program ASI Eksklusif telah ada melalui program kegiatan pengembangan kesehatan seperti melakukan penyuluhan dan konseling kepada ibu dan masyarakat agar ibu mau dan mampu menyusui bayinya dengan cara yang benar yang dimulai dari massa kehamilan, segera lahir dan neonatal dan masa menyusui (Pohan, 2011).

Target pemberian ASI Eksklusif di Dinas Kesehatan Padang Lawas Utara sebesar $85 \%$ tetapi cakupan ASI Eksklusif di Puskesmas Pangirkiran pada bulan Februari 2014 sebesar 30,5\% dan cakupan ASI Eksklusif pada bulan Agustus 2014 sebesar 36,2\% (Laporan Dinas Kesehatan Padang Lawas Utara, 2014).

\section{Permasalahan}

Masih rendahnya ibu menyusui yang memberikan ASI Eksklusif pada bayinya di Wilayah Kerja Puskesmas Pangirkiran Kecamatan Halongonan Kabupaten Padang Lawas Utara.

\section{Tujuan Penelitian}

Untuk mengetahui pengaruh faktor predisposisi (pengetahuan dan sikap), pendukung (kelancaran produksi ASI) dan pendorong (petugas kesehatan dan keluarga) ibu terhadap pemberian ASI Eksklusif di Wilayah Kerja Puskesmas Pangirkiran Kecamatan Halongonan Kabupaten Padang Lawas Utara.

\section{Manfaat Penelitian}

1. Sebagai bahan masukan bagi Dinas Kesehatan Kabupaten Padang Lawas Utara dan pihak terkait khususnya Puskesmas dalam membuat kebijakan penanggulangan masalah pemberian ASI Eksklusif.

2. Hasil penelitian ini diharapkan dapat dijadikan bahan referensi bagi penelitian yang terkait dengan perilaku pemberian ASI Eksklusif.

3. Diharapkan masyarakat pada umumnya dapat meningkatkan pengetahuannya, memperbaiki persepsi yang keliru dan keluarga dapat memberikan dukungan yang baik kepada ibu bayi sehingga pemberian ASI Eksklusif dapat ditingkatkan.

\section{METODE PENELITIAN}

\section{Jenis Penelitian}

Penelitian ini merupakan penelitian observasional dengan rancangan kasus-kontrol (casecontrol). Penelitian dilakukan dengan cara observasional retrospektif dengan tujuan untuk mengetahui pengaruh faktor predisposisi (pengetahuan, sikap), pendukung (kelancaran produksi ASI), pendorong (peran petugas kesehatan dan keluarga) terhadap pemberian ASI Eksklusif di Wilayah Kerja Puskesmas Pangirkiran Kecamatan Halongonan Kabupaten Padang Lawas Utara tahun 2015.

\section{Lokasi dan Waktu Penelitian}

Penelitian ini dilakukan di Wilayah Kerja Puskesmas Pangirkiran Kecamatan Halongonan Kabupaten Padang Lawas Utara. Penelitian ini dilakukan pada bulan September s/d Oktober 2015.

\section{POPULASI DAN SAMPEL}

\section{Populasi}

Populasi adalah keseluruhan obyek penelitian atau obyek yang diteliti (Notoatmodjo, 2010). Populasi dalam penelitian ini adalah semua ibu menyusui yang memiliki bayi usia 6-12 bulan yang berada di wilayah kerja Puskesmas Pangirkiran yaitu sebanyak 185 orang. Dari 185 ibu menyusui jumlah ibu yang memberikan ASI Eksklusif sebanyak 72 orang dan yang tidak memberikan ASI Eksklusif sebanyak 113 orang.

\section{Sampel}

Sampel penelitian adalah sebagian dari keseluruhan objek yang diteliti dan dianggap mewakili seluruh populasi (Notoatmodjo, 2010). Pengambilan sampel dilakukan dengan cara purposive sampling (sampel bertujuan), dimana sampel kontrol sejumlah 1:1 dari jumlah sampel kasus yang sesuai dengan kriteria sebagai berikut (Sastroasmoro, 2007) :

Sampel kasus dalam penelitian ini adalah ibu menyusui yang meliputi kriteria sebagai berikut :

1. Responden ibu menyusui yang tercatatat di wilayah kerja Puskesmas Pangirikiran Kecamatan Halongonan

2. Dinyatakan memberikan ASI Eksklusif

3. Bertempat tinggal di Kecamatan Halongonan Kabupaten Padang Lawas Utara

Sampel kontrol dalam penelitian ini adalah ibu menyusui yang meliputi kriteria sebagai berikut :

1. Responden ibu menyusui yang tercatatat di wilayah kerja Puskesmas Pangirikiran Kecamatan Halongonan

2. Dinyatakan tidak memberikan ASI Eksklusif

3. Bertempat tinggal di Kecamatan Halongonan Kabupaten Padang Lawas Utara 
Jadi, didapat jumlah sampel kontrol sebanyak 72 orang responden dan jumlah sampel kasus sebanyak 72 responden.

\section{METODE PENGUMPULAN DATA}

\section{Data Primer}

Data primer yang diperlukan dalam penelitian ini meliputi: pengetahuan, sikap, kelancaran produksi ASI dukungan petugas kesehatan dan dukungan keluarga ibu terhadap pemberian ASI ekslusif yang diperoleh melalui wawancara langsung dengan responden menggunakan kuesioner yang diberikan kepada responden.

\section{Data Sekunder}

Data sekunder diperoleh dari kantor Kecamatan Halongonan, yaitu data mengenai demografi penduduk serta gambaran umum mengenai Kecamatan Halongonan dan jumlah ibu yang memiliki bayi usia 612 bulan diambil dari Puskesmas Pangirkiran Kecamatan Halongonan.

\section{Teknik Pengolahan Data}

1. Pengetahuan adalah pemahaman ibu tentang pola menyusui secara Eksklusif.

Pengetahuan tentang ASI Eksklusif disiapkan kuesioner sebanyak 10 pertanyaan dengan skor total 10 . Untuk jawaban benar diberikan skor 1 dan jawaban salah diberi skor 0 .

Berdasarkan total skor dari pertanyaan yang diajukan, maka tingkat pengetahuan responden ada dua (2) kategori yaitu kategori baik dan tidak baik yaitu :

a. Baik : Bila responden mampu menjawab dengan benar $\geq 75 \%$ dari seluruh petanyaan

b. Tidak Baik : Bila responden mampu menjawab dengan benar $<75 \%$ dari seluruh pertanyaan

2. Sikap adalah kesiapan ibu untuk bertindak secara konsisten terhadap perilaku menyusui secara eksklusif yang diukur dengan kuisioner. Penilaiannya yaitu:

Skor 1 untuk jawaban sangat tidak setuju (STS)

Skor 2 untuk jawaban tidak setuju (TS)

Skor 3 untuk jawaban ragu-ragu (RR)

Skor 4 untuk jawaban setuju (S) dan

Skor 5 untuk jawaban sangat setuju (SS)

Berdasarkan total skor dari pertanyaan sikap yang diajukan, maka diklasifikasikan dalam dua (2) kategori yaitu:

a. Baik: Bila jawaban nilai (skor) responden $\geq$ $75 \%$ dari total skor

b. Tidak baik : Bila jawaban nilai (skor) responden $<75 \%$ dari total skor

3. Kelancaran produksi ASI adalah faktor pendukung yang pada prinsipnya adalah ibu menyusui umumnya makan 6 kali sehari sesuai dengan frekuensi menyusui bayi yang diukur berdasarkan 10 pertanyaan yang diajukan dengan skor 10. Anjuran yang mendukung (Ya) bernilai 1 sedangkan yang tidak mendukung (Tidak) bernilai 0 .

Berdasarkan total skor dari 10 pertanyaan yang diajukan, maka diklasifikasikan dalam 2 (dua) kategori yaitu:

a) Mendapat dukungan, apabila menjawab $\geq 75 \%$ dari skor total

b) Tidak mendapat dukungan, apabila menjawab $<75 \%$ dari skor total

4. Dukungan keluarga adalah anjuran anggota keluarga terutama suami atau orangtua yang mendukung ataupun tidak mendukung perilaku pemberian ASI eksklusif yang diukur berdasarkan 10 pertanyaan yang diajukan dengan skor 10 . Anjuran yang mendorong (Ya) bernilai 1 sedangkan yang tidak mendorong (Tidak) bernilai 0 .

Berdasarkan total skor dari 10 pertanyaan yang diajukan, maka diklasifikasikan dalam 2 (dua) kategori yaitu:

a) Mendapat dorongan, apabila menjawab $\geq 75 \%$ dari skor total

b) Tidak mendapat dorongan, apabila menjawab $<75 \%$ dari skor total

5. Dukungan petugas kesehatan adalah anjuran petugas kesehatan tentang pemberian Asi Eksklusif yang diukur berdasarkan 10 pertanyaan yang diajukan dengan skor 10. Anjuran yang mendukung bernilai 1 sedangkan yang tidak mendukung bernilai 0 .

Berdasarkan total skor dari 10 pertanyaan yang diajukan, maka diklasifikasikan dalam 2 (dua) kategori yaitu:

a) Mendapat dorongan, apabila menjawab $\geq 75 \%$ dari skor total

b) Tidak mendapat dorongan, apabila menjawab $<75 \%$ dari skor total

\section{Metode Analisis Data}

Setelah pengolahan data, tahap selanjutnya adalah menganalisa data dengan menggunakan aplikasi perangkat analisis statistik. Analisi yang dilakukan pada penelitian ini terbagi 2 analisa yaitu analisis univariat dan bivariat.

\section{HASIL DAN PEMBAHASAN}

\section{Pengaruh Pengetahuan Responden Terhadap Pemberian ASI Eksklusif}

Hasil Penelitian menunjukkan bahwa ibu yang berpengetahuan baik 1.4 kali kemungkinan memberikan ASI Eksklusif terhadap bayinya dibandingkan dengan ibu yang tidak berpengetahuan baik dengan nilai rasio prevalensi $=1.406$ dengan interval kepercayaan 95\% (1.022 - 1.935).

Hasil penelitian ini sejalan dengan hasil penelitian yang telah dilaksanakan sebelumnya oleh Wati, dkk (2013) di wilayah kerja Puskesmas Mandalle Kab. Pangkep, diperoleh hasil pengaruh pengetahuan dengan pemberian ASI Eksklusif $(p=0,000)$, dimana 
kesimpulan dari penelitian tersebut terdapat hubungan pengetahuan dengan pemberian ASI Eksklusif.

Sehubungan dengan perihal diatas pengetahuan dapat diibaratkan sebagai suatu alat yang dipakai manusia di dalam menyelesaikan persoalan yang dihadapi. Misalnya pengetahuan tentang manfaat ASI Eksklusif dapat digunakan oleh seorang ibu dalam memahami bagaimana cara memanfaatkannya. Pengetahuan dapat diperoleh seseorang melalui melihat, mendengar atau mengalami suatu kejadian yang nyata, selain itu dapat diperoleh melalui belajar di bangku pendidikan baik bersifat formal maupun informal. Pengetahuan diperoleh dari pengalaman, baik dari diri sendiri maupun dari orang lain. Pengetahuan lebih bersifat pengenalan suatu benda atau sesuatu hal secara obyektif. Pengetahuan ibu tentang ASI Eksklusif diharapkan akan menjadi dasar untuk bersikap positif terhadap pemberian ASI kepada bayinya. Dan selanjutnya akan mendorong ibu untuk memberikan ASI kepada bayinya.

\section{Pengaruh Sikap Responden Terhadap Pemberian ASI Eksklusif}

Hasil Penelitian menunjukkan bahwa ibu yang mempunyai sikap baik 1.6 kali kemungkinan memberikan ASI Eksklusif terhadap bayinya dibandingkan dengan ibu yang mempunyai sikap tidak baik dengan nilai rasio prevalensi $=1.623$ dengan interval kepercayaan $95 \%(1.114-2.365)$. Hal ini berarti sikap yang baik akan mendorong responden untuk dapat memberikan ASI secara ekslusif dan sempurna sampai usia 6 bulan secara terus menerus.

Hasil penelitian ini sejalan dengan hasil penelitian yang telah dilaksanakan sebelumnya oleh Pohan (2011) di wilayah kerja Puskesmas Sitinjak Kecamatan Angkola Barat Kabupaten Tapanuli Selatan, menyimpulkan bahwa sikap berpengaruh secara signifikan terhadap pemberian ASI eksklusif dengan nilai $p=0,034$.

Menurut Ahmadi (2004), sikap dibedakan menjadi: (1). Sikap positif, yaitu sikap yang menunjukkan atau memperlihatkan, menerima, menyetujui terhadap norma-norma yang berlaku dimana individu itu berada, dan (2). Sikap negatif, yaitu menunjukkan penolakan atau tidak menyetujui terhadap norma-norma yang berlaku dimana individu itu berada. Pengukuran sikap dapat dilakukan secara langsung atau tidak langsung. Secara langsung dapat dinyatakan pendapat atau pertanyaan respon terhadap suatu objek, secara tidak langsung dapat dilakukan dengan pertanyaan atau hipotesis kemudian dinyatakan pendapat responden.

\section{Pengaruh Kelancaran Produksi ASI Responden Terhadap Pemberian ASI Eksklusif}

Hasil penelitian di wilayah kerja Puskesmas Pangirkiran menunjukkan bahwa ibu yang mendapat dukungan kelancaran produksi ASI 2,5 kali kemungkinan memberikan ASI Eksklusif terhadap bayinya dibandingkan dengan ibu yang tidak mendapat dukungan kelancaran produksi ASI dengan nilai rasio prevalensi $=2.546$ dengan interval kepecayaan $95 \%$ (1.835 - 3.532) Hal ini berarti semakin lancar produksi ASI responden akan meningkatkan responden dalam memberikan ASI Ekslusif.

Menurut Siregar (2004), kelancaran produksi ASI dipengaruhi oleh beberapa faktor, yaitu: makanan ibu, ketentraman jiwa dan pikiran ibu, pengaruh persalinan dan klinik bersalin, penggunaaan alat kontrasepsi yang mengandung estrogen dan progesteron dan perawatan payudara.

Menurut Arini (2012) cara untuk meningkatkan produksi ASI, yaitu dengan cara menyusui bayi lebih sering, membiarkan bayi mendapatkan ASI selama bayi inginkan bayi biasanya menyusui 6 kali tiap hari, tambahlah menjadi tujuh atau delapan kali. Ketika membiarkan bayi menyusui lebih sering, tubuh ibu akan menerima respon untuk menghasilkan lebih banyak susu.

\section{Pengaruh Dorongan Keluarga Responden Terhadap Pemberian ASI Eksklusif}

Hasil penelitian di wilayah kerja Puskesmas Pangirkiran menunjukkan bahwa ibu yang mendapat dorongan dari keluarga 1,7 kali kemungkinan memberikan ASI Eksklusif terhadap bayinya dibandingkan dengan ibu yang tidak mendapat dorongan dari keluarga dengan nilai rasio prevalensi $=$ 1.690 dengan interval kepercayaan 95\% (0.962 2.968). Hal ini berarti semakin besar dukungan keluarga responden akan meningkatkan responden dalam memberikan ASI Ekslusif.

Hasil penelitian ini sejalan dengan hasil penelitian yang telah dilakukan oleh Rahmawati, dkk (2013) di wilayah kerja Puskesmas Bonto Cani Kabupaten Bone, didapat hasil dukungan keluarga $(\mathrm{p}=0,000)$, dimana kesimpulan dari penelitian tersebut terdapat hubungan dukungan keluarga yang signifikan dengan pemberian ASI Eksklusif.

Menurut Sudiharto (2007), dukungan keluarga mempunyai hubungan dengan suskesnya pemberian ASI ekslusif kepada bayi. Dukungan keluarga adalah dukungan untuk memotivasi ibu memberikan ASI ekslusif saja kepada bayinya sampai usia 6 bulan, memberikan dukungan psikologis kepada ibu dan mempersiapkan nutrisi yang seimbang kepada ibu.

Dukungan keluarga merupakan faktor pendukung yang pada prinsipnya adalah suatu kegiatan baik bersifat emosional maupun psikologis yang diberikan kepada ibu menyusui dalam memberikan ASI. Seorang ibu yang tidak pernah mendapatkan nasehat atau penyuluhan tentang ASI dari keluarganya dapat mempengaruhi sikapnya ketika ia harus menyusui sendiri bayinya (Lubis, 2000).

\section{Pengaruh Dorongan Petugas Kesehatan Responden Terhadap Pemberian ASI Ekslusif}

Hasil penelitian di Wilayah Kerja Puskesmas Pangirkiran menunjukkan bahwa ibu yang mendapat dorongan dari petugas kesehatan 3.6 kali kemungkinan 
memberikan ASI Eksklusif terhadap bayinya dibandingkan dengan ibu yang tidak mendapat dorongan dari peugas kesehatan, dengan nilai prevalensi rasio $=3.611$ dengan interval kepercayaan $95 \%(1.967-6,628)$

Peran petugas kesehatan ini adalah bentuk respon yang diberikan petugas kesehatan dalam memberikan informasi kesehatan selama pemberian ASI, memberi bimbingan dalam menangani permasalahan selama pemberian ASI ekslusif, memberikan pelayanan yang baik, melakukan kunjungan rumah untuk memantau pelaksanaan menyusui, memfasilitasi kebutuhan ibu selama masa menyusui, memberikan informasi tentang ASI Ekslusif dan meningkatkan kepercayaan diri ibu untuk memberikan ASI ekslusif.

Hasil penelitian ini sejalan dengan hasil penelitian yang telah dilakukan oleh Suprapti (2010) di Puskesmas Ponorogo Utara Kab. Ponorogo menyimpulkan bahwa ada pengaruh positif dan signifikan pemberian penyuluhan oleh petugas kesehatan tentang pemberian ASI.

Hal yang sama juga disampaikan oleh Rahmawati (2009) yang dalam penelitiannya di Kelurahan Pedalangan Kecamatan Banyumanik Kota Semarang menyimpulkan bahwa dukungan petugas kesehatan berpengaruh terhadap pemberian ASI eksklusif.

Pemberian ASI secara Ekslusif ada hubungannya dengan peran petugas kesehatan, sikap dan perhatian oleh para ahli kesehatan yang berkaitan dengan menyusui sangat diperlukan terutama dalam menghadapi promosi pabrik pembuat susu formula dan pemberian makanan pendamping ASI seperti pisang, madu, bubur nasi. Posisi strategis dari peranan instansi kesehatan dan para petugas kesehatan di Indonesia terutama di puskesmas sangat bermanfaat bagi pelaksanaan kegiatan operasional pemasyarakatan ASI.

\section{KESIMPULAN}

Berdasarkan hasil penelitian, maka dapat disimpulkan sebagai berikut :

1. Ibu yang berpengetahuan baik 1.4 kali kemungkinan memberikan ASI Eksklusif terhadap bayinya dibandingkan dengan ibu yang tidak berpengetahuan baik, dengan rasio prevalensi 1.406 dengan interval kepercayaan $95 \%(1.022-1.935)$.

2. Ibu yang mempunyai sikap baik 1.6 kali kemungkinan memberikan ASI Eksklusif terhadap bayinya dibandingkan dengan ibu yang mempunyai sikap tidak baik, dengan rasio prevalensi 1.623 dengan interval kepercayaan $95 \%(1.114-2.365)$.

3. Ibu yang mendapat dukungan kelancaran produksi ASI 2,5 kali kemungkinan memberikan ASI Eksklusif terhadap bayinya dibandingkan dengan ibu yang tidak mendapat dukungan kelancaran produksi ASI dengan rasio prevalensi 2.546 dengan interval kepercayaan $95 \%(1.835-3.532)$.

4. Ibu yang mendapat dorongan dari keluarga 1,7 kali kemungkinan memberikan ASI Eksklusif terhadap bayinya dibandingkan dengan ibu yang tidak mendapat dorongan dari keluarga, dengan rasio prevalensi $=1.690$ dengan interval kepercayaan $95 \%(0.962-2.698)$.

5. Ibu yang mendapat dorongan dari petugas kesehatan 3.6 kali kemungkinan memberikan ASI Eksklusif terhadap bayinya dibandingkan dengan ibu yang tidak mendapat dorongan dari peugas kesehatan, dengan rasio prevalensi $=3.611$ dengan interval kepercayaan $95 \%(1.967-6,628)$.

\section{SARAN}

Berdasarkan dari penelitian yang telah dilakukan dan untuk menanggulangi pemberian ASI tidak Eksklusif pada masyarakat maka sebagai saran yang direkomendasikan:

1. Diharapkan kepada petugas kesehatan di Puskesmas Pangirkiran untuk lebih meningkatkan penyuluhan tentang ASI Eksklusif kepada masyarakat agar pemberian ASI Eksklusif kepada bayi dapat ditingkatkan.

2. Hendaknya masyarakat menambah pengetahuan tentang ASI Eksklusif sehingga dapat memberikan ASI kepada bayi secara Eksklusif.

\section{DAFTAR PUSTAKA}

Dinkes Paluta, 2014, Laporan Profil Dinas Kesehatan Padang Lawas Utara, Gunung Tua.

Kristiyansari, W., 2009, ASI Menyusui Dan Sadari, Nuha Medika:Yogyakarta.

Lubis, 2000. Pengaruh Pengetahuan Keluarga Tentang Asi Dan Sikap Ibu Di Dalam Memberikan Asi Pada Bayinya. Universitas Sumatra Utara. Medan

Notoatmodjo, S, 2010, Pendidikan dan Perilaku Kesehatan, Rineka Cipta, Jakarta

Pohan, E.S, 2011, Pengaruh Faktor Predisposisi, Pendorong dan Pendukung Terhadap Pemberian ASI Eksklusif, Program Pasca Sarjana Fakultas Kesehatan Masyarakat Universitas Sumatera Utara, Medan.

Rahmawati, M. D., 2009, Faktor-faktor yang Mempengaruhi Pemberian ASI Eksklusif Pada Ibu Menyusui di Kelurahan Pedalangan Kecamatan Banyumanik Kota Semarang, Jurnal KesMaDaSka, Vol 1 No. 1, (8-17) ISSN 20875002.

Rahmawati, A., 2013, Hubungan Antara Karakteristik Ibu, Peran Petugas Kesehatan Dan Dukungan Keluarga Dengan Pemberian ASI Eksklusif Di Wilayah Kerja Puskesmas Bonto Cani Kabupaten Bone, Program Studi Ilmu Gizi 
Fakultas Kesehatan Masyarakat Universitas Hasanuddin Makassar, Makassar.

Sastroasmoro, 2007, Dasar-dasar Metodologi Penelitian Klinis. Edisi ke-3. Sagung Seto: Jakarta.

Siregar, A., 2004, Pemberian ASI Ekslusif dan Faktorfaktor yang Mempengaruhinya, FKM USU, Medan.

Wati, 2013, Faktor - Faktor Yang Mempengaruhi Ibu Menyusui Dalam Pemberian ASI Eksklusif Pada
Bayi Usia 0-6 Bulan Di Wilayah Kerja Puskesmas Mandalle Kab. Pangkep, Volume 3 Nomor 1 Tahun 2013, ISSN: 2302-1721.

Yuliarti, I.D, 2008, Hubungan Pengetahuan dan Sikap Ibu Dengan Perilaku Pemberian Asi Eksklusif, Program Pasca Sarjana Program Studi Kedokteran Keluarga, Surakarta. 